\title{
OPTIMALISASI PENJADWALAN PROYEK JEMBATAN GIRDER GUNA MENCAPAI EFEKTIFITAS PENYELESAIAN DENGAN METODE PERT DAN CPM PADA PT BUANA MASA METALINDO
}

\author{
Dewi Taurusyanti \\ Dosen Tetap Fakultas Ekonomi Universitas Pakuan \\ Lecturer of Economic Faculty at Pakuan University \\ Muh. Firki Lesmana \\ Mahasiswa Fakultas Ekonomi Universitas Pakuan \\ Student of Economic Faculty at Pakuan University
}

\begin{abstract}
ABSTRAK
PT Buana Masa Metalindo berfokus pada penyediaan fabrikasi logam untuk berbagai sektor industri, seperti minyak, gas, pertambangan, industri dan otomotif. Proyek yang sedang berlangsung saat ini jembatan girder. Sebuah jembatan gelagar adalah kualitas tinggi jembatan rangka baja ringan, yang bergerak dan sangat strategis dalam mendukung pekerjaan konstruksi. Masalah terletak pada timefram proyek yang dapat diselesaikan sesuai dengan pergeseran waktu ditetapkan pada 42 hari di awal, untuk 35 hari. Metode PERT-CPM dapat pemanfaatannya untuk mengelola proyek waktu kerja menjadi lebih efisien dan efektif. Dalam rangka mengurangi dampak dari keterlambatan proyek dan biaya overruns, tiga metode alternatif dapat ditarik; (i) tambahan tenaga kerja / buruh, (ii) bekerja lembur, dan (iii) subkontrak. Percepatan durasi dilakukan pada kegiatan di jalur kritis dan jumlah hari yang diberikan pada masingmasing alternatif equaled. Hasil menunjukkan bahwa tambahan tenaga kerja / buruh alternatif tahu waktu yang optimal untuk menyelesaikan proyek yang 35 hari dengan biaya total proyek Rp48,650,000.00.
\end{abstract}

Kata kunci: efektifitas, probabilitas.

\begin{abstract}
PT Buana Masa Metalindo focuses on providing metal fabrication for various industrial sectors, such as oil, gas, mining, industry and automotive. The current ongoing project is girder bridge. A girder bridge is a high quality light steel frame bridge, which is movable and is very strategic in supporting construction works. The issue lies on the project timefram which can be finished in accordance to the time shift set at 42 days in the beginning, to 35 days. PERT-CPM method can be utilizied to manage project working time become more efficient and effective. In order to reduce the impact of the project delay and cost overruns, three alternative methods can be drawn; (i) additional workforce/labours, (ii) working overtime, and (iii) subcontracting. Acceleration of duration is done on the activities at the critical path and total days that given on each alternative is equaled. Result showed that additional workforces/labours alternative figured out the optimal time to finish the project which 35 days with projects total cost Rp48,650,000.00.
\end{abstract}

Keyword: effectivity, probability.

\section{PENDAHULUAN}

Sebagaimana perkembangan industri yang semakin pesat membuat kebutuhan fasilitas pendukung seperti, tangki, kanal, pipa saluran minyak, plat baja dan semacamnya sangat diperlukan. Tidak hanya itu saja dalam memajukan kehidupan bangsa maupun dalam memfasilitasi para pelaku ekonomi mikro hingga makro, infrastruktur menjadi hal yang memang dibutuhkan seperti jembatan, pondasi, gedung perkantoran dan infrastruktur lainnya.

Proyek pada umumnya memiliki batas waktu (deadline), artinya proyek harus diselesaikan sebelum atau tepat pada waktu yang telah ditentukan. Salah satu bagian utama perencanaan proyek adalah penentuan jadwal atau 
penjadwalan. Penjadwalan secara umum, dapat diartikan sebagai penerjemah suatu rencana kegiatan proyek kedalam suatu jadwal kerja yang menunjukan urutan pelaksanaan berbagai kegiatan serta waktu dimulai dan diakhirinya setiap kegiatan yang bersangkutan.

PT Buana Masa Metalindo didirikan di Jakarta sejak tahun 1999. Perusahaan yang dulu hanya berfokus pada penyediaan fabrikasi baja ke berbagai sektor industri seperti minyak, gas, pertambangan, industri dan industri otomotif. Pada saat ini, perusahaan telah berkembang dengan kemampuan untuk memberikan solusi yang konstruktif untuk berbagai proyek infrastruktur. Saat ini, sekitar 200 orang dipekerjakan lokasi pabrik berada di Gunung Putri, Bogor di Jawa Barat. Proyek yang pada saat ini ingin diproses adalah Jembatan Girder. Jembatan Girder adalah jembatan rangka baja ringan berkualitas tinggi, yang mudah dipindah-pindah (Movable) sangat strategis dalam menunjang pembangunan.

Proyek Jembatan Girder direncanakan selesai selama 42 hari dengan 17 orang pekerja. Namun dalam pelaksanaannya pihak klien meminta adanya percepatan menjadi 35 hari. Hal ini menjadi sebuah fenomena yang perlu diteliti karena jadwal semula direncanakan menggunakan Diagram Grant.

Adapun tujuan dari penelitian ini antara lain:

1. Mengetahui penjadwalan untuk tahap - tahap pekerjaan yang perlu dilakukan PT Buana Masa Metalindo untuk menyelesaikan proyek Jembatan Girder;

2. Mengetahui tingkat efektivitas penjadwalan PT Buana Masa Metalindo untuk setiap pekerjaan yang diperlukan untuk pembuatan proyek Jembatan Girder; dan
3. Mengetahui penjadwalan dalam penyelesaian proyek Jembatan Girder dengan menggunakan metode PERT dan CPM guna mencapai efektivitas pada PT Buana Masa Metalindo.

\section{METODE PENELITIAN}

Metode penelitian yang digunakan penulis yaitu metode kualitatif dan kuantitatif, dengan menggunakan teknik penelitian statistik observasi. Untuk mendukung hasil yang diharapkan, metode PERT dan CPM digunakan sebagai alat bantu untuk mencapai efektivitas penyelesaian proyek Jembatan Girder pada PT Buana Masa Metalindo.

\section{HASIL DAN PEMBAHASAN}

Berdasarkan data melalui diagram Grant yang diberikan perusahaan, penjadwalan Proyek Jembatan Girder dapat diidentifikasi efektivitas waktunya sesuai tahap-tahap utama aktivitasnya.

Hasil pada penelitian menyatakan bahwa Proyek Jembatan Girder dapat diselesaikan selama 42 hari sedangkan perubahan yang terjadi untuk adanya percepatan jadwal selama 35 hari. Artinya, belum adanya efektivitas penjadwalan yang tepat sebagaimana perubahan penjadwalan yang terjadi.

\subsection{Evaluasi dengan Metode PERT pada Proyek Jembatan Girder. \\ Dalam menentukan tiga taksiran} waktu (Optimistic, Realistic dan Pessimistic), dilakukan penghitungan distribusi peluang beta yang diperoleh dengan cara menghitung nilai rata - rata tertimbang (weighted average) dari ketiga taksiran waktu untuk setiap pekerjaan proyek Jembatan Grider. 


\subsection{Penentuan Jaringan Kritis (CPM) pada Proyek Jembatan Girder}

Penentuan jaringan kritis berguna untuk menentukan dimana letak aktivitas proyek Jembatan Girder yang harus dipercepat. Sebelumnya, membuat terlebih dahulu waktu mulai dan waktu berakhir untuk setiap kegiatan proyek Jembatan Ginder.

Dari hasil analisis jalur kritis terdapat 8 aktivitas kritis yaitu pada

aktivitas A1, B1, C4, D1, E1, F2, G1 dan G2. Pada aktivitas kritis inilah dapat dilakukan Project Crashing agar Proyek Jembatan Girder yang awalnya 42 hari dapat mencapai efektivitas waktu selama 35 hari.

\subsection{Distribusi Peluang untuk Penyelesaian Proyek}

$$
Z=(\text { batas waktu }- \text { waktu penyelesaian yang diharapkan }) / \sigma p
$$

Dimana, $\mathrm{Z}=$ jumlah deviasi standar batas waktu atau target waktu yang berada diantara rata - rata atau waktu yang diharapkan.

$$
\begin{aligned}
\mathrm{Z} & =(42-35) / 1.915724406 \\
& =3,653970257
\end{aligned}
$$

Dari hasil perhitungan distribusi normal, nilai $\mathrm{Z}$ atau peluang 3,653970257 berarti ada peluang 99, $98 \%$ penyelesaian proyek Jembatan Girder dapat dicapai selama 35 hari.

\subsection{Efektivitas Waktu Proyek Jembatan Girder \\ Berdasarkan hasil pada Jalur} Kritis telah diperoleh sebanyak 8 aktivitas kritis yaitu pada aktivitas A1, B1, C4, D1, E1, F2, G1 dan G2. Pada Aktivitas Kritis inilah dapat dilakukan Project Crashing agar efektivitas waktu Proyek Jembatan Girder yang awalnya 42 hari dapat diselesaikan selama menjadi 35 hari. Adapun hasil perubahan waktu tersebut yaitu hasil dari crashing 1 hari untuk masing masing aktivitas tersebut ternyata bisa tercapai efektivitas waktu menjadi 35 hari. Akan tetapi untuk mencapai target 35 hari itu dapat dilakukan menggunakan crashing project dengan alternatif penambahan tenaga kerja, jam lembur, dan sub-kontrak.

\subsection{Percepatan Durasi Proyek (Project Crashing) pada Proyek Jembatan Girder \\ Ada beberapa cara untuk} mempercepat suatu kegiatan, sehingga didapat alternatif terbaik sesuai dengan kondisi kontraktor pelaksana. Cara cara tersebut antara lain:

1. Perhitungan Crashing dengan Alternatif Penambahan Tenaga Kerja

Berdasarkan perbandingan sebelum dan sesudah crashing dengan alternatif penambahan tenaga kerja dapat disimpulkan biaya normal yang diperlukan untuk membiayai tenaga kerja dalam penyelesaian Proyek Jembatan Girder sebesar Rp50,190,000.00 selama 42 hari. Namun dengan alternatif penambahan tenaga kerja proyek dapat terselesaikan selama 35 hari dengan biaya sebesar Rp48,650,000.00. Artinya, terjadi minimumisasi biaya sebesar Rp1,540,000. 
2. Perhitungan Crashing dengan Alternatif Penambahan Jam Lembur

Berdasarkan perbandingan sebelum dan sesudah crashing dengan alternatif penambahan jam lembur dapat disimpulkan disimpulkan Biaya Normal yang diperlukan untuk membiayai tenaga kerja dalam penyelesaian Proyek Jembatan Girder sebesar Rp50,190,000.00 selama 42 hari. Namun dengan alternatif penambahan Jam Lembur proyek dapat terselesaikan selama 35 hari dengan biaya sebesar Rp56,105,000.00. Artinya, terjadi kenaikan biaya sebesar: Rp5,915,000.

3. Perhitungan Crashing dengan Alternatif Sub-Kontrak

Berdasarkan perbandingan sebelum dan sesudah crashing dengan alternatif sub-kontrak dapat disimpulkan Biaya Normal yang diperlukan untuk membiayai tenaga kerja dalam penyelesaian Proyek Jembatan Girder sebesar Rp50,190,000.00 selama 42 hari. Namun dengan alternative SubKontrak proyek dapat terselesaikan selama 35 hari dengan biaya sebesar 62,575,000.00. Artinya, terjadi kenaikan biaya yang signifikan sebesar: Rp12,385,000.

4. Perbandingan Keadaan Sebelum dan Sesudah Crashing dengan berbagai Alternatif

Berdasarkan perbandingan keadaan sebelum dan sesudah crashing dengan berbagai alternatif dapat disimpulkan terjadinya peningkatan biaya akibat pemendekkan durasi pelaksanaan pekerjaan dari 42 hari kerja menjadi 35 hari kerja dengan menerapkan alternatif penambahan Jam Lembur dan Sub-Kontrak. Untuk alternatif penambahan tenaga kerja tidak mengalami kenaikan biaya bila dibandingkan dengan alternatif penambahan Jam Lembur dan Sub-Kontrak. Tidak hanya pemercepatan dengan alternatif penambahan tenaga kerja pun dapat memperkecil biaya yang ada.

\section{Kesimpulan}

1. Peluang/probabilitas pencapaian target waktu penyelesaian proyek yang diharapkan yaitu, 35 hari adalah 99,98\% dengan nilai $\mathrm{Z}$ atau peluang 3.653970257.

2. Percepatan durasi proyek dilakukan dengan menggunakan tiga alternatif, yaitu penambahan tenaga kerja, jam lembur dan subkontrak. Total biaya dengan penambahan tenaga kerja adalah Rp48,650,000.00 pada durasi 35 hari kerja, biaya proyek dengan kerja lembur adalah Rp56,105,000.00 pada durasi 35 hari kerja dan biaya proyek dengan sub-kontrak sebesar Rp62,575,000.00 dengan durasi 35 hari kerja. Berdasarkan hasil analisis dapat diketahui bahwa percepatan durasi dari ketiga alternatif tersebut adalah 7 hari kerja atau $16,67 \%$ dari durasi normal, namun menghasilkan biaya yang berbeda. Pada alternatif penambahan tenaga kerja terjadi penurunan sebesar Rp1,540,000.00 atau 3,07\% dari total biaya proyek normal. Sedangkan, penambahan jam lembur menghasilkan kenaikan biaya sebesar Rp5,915,000 atau $10,54 \%$ dari total biaya proyek 
normal. Total biaya proyek pada alternatif sub-kontrak terjadi kenaikan yang paling besar dibandingkan penambahan tenaga kerja ataupun jam lembur sebesar Rp12,385,000 atau 19,79 dari total biaya proyek normal.

3. Durasi dan biaya proyek optimal untuk menyelesaikan Proyek Jembatan Girder adalah dengan efektivitas waktu yang tercapai selama 35 hari dan biaya sebesar Rp48,650,000.00 dengan menggunakan alternatif penambahan tenaga kerja.

\section{Daftar Pustaka}

Alan Walter Steiss. 2005. Strategic Facilities Planning. LEXINGTON BOOKS: USA.

Aulia Ishak. 2010. Manajemen Operasi. Graha Ilmu. Yogyakarta.

Chuck Williams. 2008. Management. SOUTH-WESTERN: USA.

Clive Gray (penerjemah: Gembong Tjitrosoepomo). 1985. Pengantar Evaluasi Proyek. PT Gramedia Pustaka Utama. Jakarta.

Eddy Herjanto. 2007. Manajemen Operasi. Edisiketiga. Grasindo. Jakarta.

Eka Dannyati. 2010. “Optimalisasi Pelaksanaan Proyek dengan Metode PERT \& CPM". Diakses pada tanggal 25 Februari 2014 dari PDF search engine.

George R. Terry dan Leslie W. Rue (Penerjemah: G. A. Ticoalu).
2005. Dasar - dasar Manajemen. Bumi Aksara. Jakarta.

Irham Fahmi. 2012. Manajemen Produksi \& Operas. ALFABETA. Bandung.

Jack Gido dan James P. Clements. 2012. Succesfull Project Management. Fifth Edition. SOUTH-WESTERN Cengage Learning: Canada..

Jay Heizer dan Barry Render (penerjemah: Chriswan Sungkono). 2011. Operations Management (Manajemen Operasi). Salemba Empat. Jakarta.

Murfidin Haming dan Mahfud Nurnajamudin. 2011. Manajemen Produksi Modern. PT Bumi Aksara. Jakarta.

Nur Indiantoro dan Bambang Supomo. 2009. Metodologi Penelitian Bisnis. BPFE. Yogjakarta.

Portas M. Pardede (penerjemah: Aria Farahmita). 2007. Manajemen Produksi \& Operasi. GRASINDO. Jakarta.

S N Chary. 2009. Production \& Operations Management, the Mc Graw Hill Company: New Delhi.

Sugiyono. 2007. Metodologi Penelitian Bisnis. ALFABETA. Bandung.

Stephen P. Robbins dan Mary Coulter (Penerjemah: Suryadi Saat \& Wibi Hardani). 2010. Management, Erlangga. Ciracas. Jakarta. 